\title{
Cenplesto
}

\section{Memória, patrimônio, bibliotecas nacionais e a construção da identidade coletiva}

\author{
Marcia Rodrigues \\ Doutoranda; Universidade Federal de Pelotas (UFPel), Pelotas. RS, Brasil; \\ marciarodriguesfurg@gmail.com
}

\begin{abstract}
Resumo: Este trabalho visa contribuir para o entendimento da relação entre as bibliotecas e a construção da memória coletiva e suas implicações na preservação do patrimônio cultural nacional. Para tanto, realiza uma revisão teórica sobre memória e patrimônio, fundamentada em importantes estudiosos da área. Igualmente, elabora uma revisão sobre o surgimento das bibliotecas nacionais, fundamentada em autores contemporâneos. Na sequência, tece considerações a respeito da missão institucional das bibliotecas nacionais, traçando um breve esboço da trajetória histórica da Biblioteca Nacional brasileira, demonstrando seu papel na salvaguarda do patrimônio bibliográfico do país.
\end{abstract}

Palavras-chave: Memória social. Patrimônio cultural. Patrimônio bibliográfico. Biblioteca Nacional (Brasil).

\section{Introdução}

A história das bibliotecas tem início paralelamente ao surgimento da escrita. As primeiras instituições das quais se tem notícia tinham uma função marcadamente utilitária: serviam como depósitos onde se guardavam documentos de maneira sistemática e organizada. Ao longo de sua evolução, assumiram diferentes funções, ampliando sua atribuição meramente utilitarista e, segundo sua missão, acervo e público a que se destinam, dividiram-se em diferentes categorias: nacionais, públicas, privadas, acadêmicas, infantis, especializadas, temáticas etc.

Independentemente da sua tipologia, bibliotecas passaram ao longo do tempo a ser identificadas como organismos culturais, instituições onde se promove a salvaguarda do patrimônio bibliográfico, estabelecimentos onde é possível ter acesso ao conhecimento produzido e acumulado pelos seres humanos, lugares onde a memória coletiva encontra sua materialização através do registro escrito e de onde é 
possível obter referências por meio das quais nossa memória individual e coletiva e nosso patrimônio cultural se fazem perceber.

Neste contexto, as bibliotecas nacionais, vistas como estabelecimentos cuja função primordial reside em salvaguardar e tornar acessível a herança cultural deixada pelos cidadãos de determinado país, através de sua mais evoluída forma de registro do pensamento que é a escrita, contribuem efetivamente para a construção da memória coletiva da nação.

Buscando compreender de que maneira estas instituições podem contribuir com o processo de salvaguarda do patrimônio cultural e de que forma se relacionam com a memória coletiva da nação à qual pertencem, serão abordadas neste artigo algumas questões teóricas referentes à memória social, patrimônio cultural e patrimônio bibliográfico, tendo como objeto de estudo a Biblioteca Nacional Brasileira, localizada na cidade do Rio de Janeiro. Para tanto, faz uso da revisão bibliográfica, trazendo uma síntese dos principais teóricos que contribuíram para o estabelecimento das noções de memória e patrimônio cultural, bem como reflexões a respeito da missão institucional das bibliotecas nacionais e seu papel na salvaguarda do patrimônio bibliográfico nacional.

O presente estudo faz parte da pesquisa de doutoramento da autora e constitui uma parcela do estudo sobre a relação existente entre a preservação do patrimônio bibliográfico e o papel das bibliotecas nacionais neste processo.

\section{Memória social e patrimônio cultural}

Maurice Halbwachs, importante filósofo e sociólogo francês, desenvolveu o conceito de memória coletiva em duas importantes obras, tendo sido a segunda publicada postumamente: Os quadros sociais da memória (1925) e A memória coletiva (1950). Para Halbwachs (1990) a memória coletiva não é e nem pode ser considerada ponto de partida para o estudo de uma comunidade, pois ela não parte do vazio, do nada, mas é uma construção que ocorre tanto no plano individual quanto no coletivo. A memória é adquirida à medida que o indivíduo toma como suas as lembranças do grupo com o qual se relaciona, ou seja, há um processo de 
apropriação de representações coletivas pelo sujeito em interação com outros. (HALBWACHS, 1990).

Ainda, segundo o autor, de cada época de nossas vidas guardamos memórias, reproduzidas incessantemente, através das quais se perpetua o sentimento da nossa identidade. Porém, por se tratar de memórias de outras épocas, estas perderam sua forma e seu aspecto original. Sendo assim, para tornar presentes estas memórias, quanto maior for o número de testemunhos escritos e orais aos quais tivermos acesso, mais próximo chegaremos da reconstituição do passado original, já que para rememorar efetivamente um fato do passado precisaríamos ter condições de evocar, ao mesmo tempo e sem exceção, todas as influências sobre nós exercidas na época do acontecimento.

Para Halbwachs $(1990 ; 2004)$ a memória individual é, portanto, apenas uma parte e um aspecto da memória do grupo. Mesmo quando esta é, aparentemente, mais íntima, se preserva uma lembrança duradoura na medida em que se refletiu sobre ela, ou seja, esta foi vinculada com os pensamentos do meio social. O autor conclui que rememorar não é reviver, mas refazer, reconstruir, repensar experiências passadas com imagens e ideias contemporâneas.

Retomando em parte o conceito de memória coletiva proposto por Halbwachs, Joel Candau, professor de Antropologia da Memória da Universidade de Nice-Sophie Antipolis (França) propõe uma recategorização das memórias a partir de três qualidades: (1) a protomemória, (2) a memória propriamente dita ou memória de evocação e (3) a metamemória. A protomemória, segundo Candau (2011), é aquele tipo de memória que não gera arquivo, memória de baixo-nível ou memóriatrabalho: é a memória social incorporada nos gestos, na linguagem, na prática social, cuja realização se dá de maneira quase automática. O segundo tipo de memória, a memória evocação ou memória propriamente dita parte das lembranças individuais e pessoais de cada ser humano. Já a terceira memória, a metamemória, diz respeito à construção identitária. É a representação que fazemos das nossas lembranças. (CANDAU, 2011).

O conceito de metamemória de Candau dialoga com o conceito de memória coletiva de Halbwachs na medida em que ambos creem que as memórias individuais se formam dentro da memória coletiva, porém dentro deste conceito, quem lembra 
ou rememora algo é o indivíduo e não a sociedade ou o grupo com o qual é compartilhado o evento passado.

De certa forma, Candau aperfeiçoa o conceito de memória coletiva ao reduzir a possibilidade de confusão entre memórias individuais e coletivas [...]. Ele soluciona o problema propondo que as duas primeiras memórias, a protomemória e a memória propriamente dita, constituem faculdades individuais, $\log 0$, não podem ser compartilhadas. Para ele, só a terceira memória, a metamemória, aquela que se refere à memória coletiva, pode ser compartilhada, pois é um conjunto de representações da memória. (MATHEUS, 2011, p. 304).

Candau (2011) reafirma a importância do espaço na construção e evocação da memória, assim como Halbwachs o faz em sua teoria, e observa que indivíduos "desterritorializados", ou seja, que perderam os referenciais que os orientavam no mundo, tornam-se sujeitos sem identidade, pois perderam também sua memória. Conclui-se, a partir destes dois importantes teóricos, que a memória social se materializa através da utilização de símbolos identitários, que por sua vez constituem os lugares de memória. "Os lugares de memória se configuram [...] como instâncias físicas ou virtuais que se organizam para servir de apoio à salvaguarda da materialidade simbólica concebida como elemento de representação coletiva." (SILVEIRA, 2010, p. 68).

Os conceitos de nação e de patrimônio surgem basicamente a partir desta crença: indivíduos que compartilham uma memória, que acreditam pertencer ao mesmo grupo constituído pelas mesmas lembranças, que creem ter um passado comum que deve ser, portanto, preservado e novamente compartilhado com as gerações que os sucedem.

Ao observar a noção contemporânea de patrimônio cultural, percebe-se que está intimamente ligada à história econômica e social da França, especificamente com a ocorrência da Revolução Francesa, ou seja, é a partir da Revolução, com a necessidade de criar um elo comum que justifique o cidadão e sua história que se cria a noção de compartilhamento, tendo em mente que quanto mais coesos forem os grupos sociais, maior a capacidade de construir memórias fortes (é o caso, por exemplo, do grupo família). Antes, porém, deste marcante acontecimento, o conceito de patrimônio já vinha sofrendo pequenas modificações em função das 
transformações pelas quais vinha passando a sociedade, ampliando a noção de patrimônio aristocrática característica da antiguidade clássica e acrescentando-lhe valor religioso, com a passagem para a Idade Média, período em que a Igreja Católica exerceu forte influência sobre a vida social, econômica, política e cultural das comunidades. Assim, neste período o patrimônio passou não somente a representar um legado familiar, baseado em uma concepção exclusivamente individual, acabando por retratar, também, algo coletivo, como o culto aos santos, a exaltação dos milagres, a valorização das relíquias, a monumentalização das igrejas, entre outros elementos constituintes do patrimônio religioso.

Somente alguns séculos mais tarde, sob as óticas humanista e renascentista, surge o conceito contemporâneo de patrimônio cultural. Neste período houve uma valorização dos objetos antigos e a prática do colecionismo, fundando o que se chamou de "antiquariado" (ideia que posteriormente originou a concepção dos museus). Funari e Pelegrini (2009) salientam, porém, que o marco definitivo para a modificação do conceito tradicional de patrimônio - centrado originalmente na propriedade privada pertencente ao pai de família (o pater ou pater familias) - foi a solidificação dos Estados nacionais, resultantes especialmente das revoluções Francesa e Industrial, o que possibilitou não somente a ruptura de um padrão econômico, político e social vigente, mas o estabelecimento de uma noção de que as pessoas compartilham, de maneira homogênea, um passado comum, quer seja ele constituído de figuras de antepassados, de costumes, de tradições ou crenças. Este passado possibilita a criação de um presente e um futuro também comuns, levando à consolidação do caráter de coletividade necessário à criação de cidadãos exigido pelo novo modelo socioeconômico.

A ideia de patrimônio legitimada pela Revolução Francesa expande a noção anterior, centrada na concepção de algo passível de ser transmitido às gerações seguintes, porém totalmente voltada à figura do pai ou dos antepassados, e traz à tona a ideia de que existe um legado que une os cidadãos de uma nação entre si, promovendo a valorização e consagração daquilo que é comum ao grupo no tempo e no espaço.

Para Funari e Pelegrini (2009, p. 16), “O Estado nacional surgiu, portanto, a partir da invenção de um conjunto de cidadãos que deveriam compartilhar uma 
língua e uma cultura, uma origem e um território.”.

O destaque dado ao patrimônio nacional, porém, atinge seu auge no período que vai da primeira à segunda Grande Guerra (entre 1914 e 1945). As mesmas nações que se consolidaram como Estados nacionais (França e mais tarde Inglaterra e Estados Unidos) se tornaram impérios; concomitantemente, houve apropriação dos bens culturais e riquezas dos colonizados pelos colonizadores, já que estes concluíram ser os verdadeiros herdeiros do patrimônio cultural deixado por seus antepassados, iluminados pelas ideias nacionalistas que influenciaram estes dois acontecimentos históricos. O patrimônio estava à mercê de dois fatores do mundo moderno: o Estado nacional e o Imperialismo.

Observa-se, entretanto, que, especialmente após a década de 1960, houve uma crescente crítica ao Estado nacional e ao Imperialismo e a sociedade civil passou a não aceitar mais passivamente estas duas condições, demonstrando sua resistência através de revoltas e movimentos sociais, como os movimentos pela emancipação feminina e em prol dos direitos civis. Neste contexto a noção de patrimônio passa novamente por modificações, que levam à moderna concepção de patrimônio, com sentido consideravelmente ampliado em relação ao conceito anterior: o patrimônio cultural inclui, agora, não somente bens materiais (móveis e imóveis), mas também bens imateriais, como os saberes, os fazeres e todo o contexto que envolve a sua materialidade, sem deixar de considerar toda a diversidade presente na produção destes bens e sua importância para as comunidades às quais pertencem. Já não se concebe mais a existência de um patrimônio nacional, único e representativo de uma coletividade, engessado e materializado em bens físicos (monumentos, edifícios, objetos etc.), mas sim de um conjunto de patrimônios, de diferentes comunidades, constituído tanto de bens materiais quanto imateriais, que formam uma "teia" patrimonial e esta sim, representa, com toda sua heterogeneidade, diversidade e particularidades, o patrimônio de uma nação.

Retomando as ideias do sociólogo francês Michael Pollak, observa-se que em sua teoria este trata o patrimônio como um sistema de referências. É possível perceber nesta a relação existente entre o conceito de memória coletiva de Maurice Halbwachs, relacionando a memória aos conceitos de identidade e pertencimento, e as ideias de Pierre Nora, historiador de origem também francesa, resgatando o 
conceito de lugares de memória, lugares não apenas físicos, mas também mentais onde seria possível reviver determinadas lembranças (POLLAK, 1989, 1992).

Segundo Pollak (1992, p. 201), a memória é um conjunto de acontecimentos,

[...] dos quais a pessoa nem sempre participou mas que, no imaginário, tomaram tamanho relevo que, no fim das contas, é quase impossível que ela consiga saber se participou ou não. Se formos mais longe, a esses acontecimentos vem se juntar todos os eventos que não se situam dentro do espaço-tempo de uma pessoa ou de um grupo. É perfeitamente possível que por meio da socialização política, ou da socialização histórica, ocorra um fenômeno de projeção ou identificação com determinado passado, tão forte que podemos falar numa memória quase herdada.

$\mathrm{Na}$ perspectiva do patrimônio, pode-se ainda relacionar as reflexões de Pollak com o pensamento do antropólogo espanhol Llorenç Prats, que considera patrimônio cultural "[...] tudo aquilo que socialmente se considera digno de conservação independente de seu interesse utilitário." (PRATS, 1998, p. 63, tradução nossa). Prats vai além e afirma que o patrimônio cultural é tanto uma invenção quanto uma construção social, elaborada a partir da ativação de determinados bens e legitimada através do discurso:

\begin{abstract}
Associo os processos de invenção com a capacidade de gerar discursos sobre a realidade com vistas a adquirir cartas de natureza e, portanto, com o poder (não somente com o poder político, se como tal se entende exclusivamente ao que deriva do Estado), e associo a ideia de construção social com os processos de legitimação, ou seja, de assimilação social destes discursos mais ou menos inalterados. [...] Nenhuma invenção adquire autoridade até que se legitime como construção social e nenhuma construção social se produz espontaneamente sem um discurso prévio inventado [...] pelo poder [...]. (PRATS, 1998, p. 63-64, tradução nossa).
\end{abstract}

A partir da leitura de Pollak e Prats é possível perceber que a seleção dos elementos integrantes do patrimônio nunca ocorre de forma neutra ou inocente, porém sempre visando a uma correlação entre ideias, valores e o contexto social de onde provém, ou seja, a construção do patrimônio cultural de uma nação ocorre de maneira intencional e mesmo estratégica. Sendo assim, ao mesmo tempo em que o patrimônio serviria para fins de identificação coletiva, serviria também aos propósitos das instituições que ativam estes referenciais e que se utilizam da memória coletiva como instrumento para efetivação de seus programas e a 


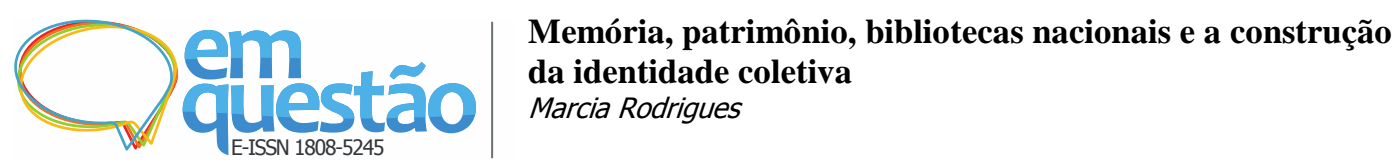

legitimação simbólica de suas ideologias identitárias.

Pierre Nora considera como importante para entender a cultura contemporânea uma questão que diz respeito ao passado e ao sentimento de pertencimento a um determinado grupo social, ou seja, entre a consciência coletiva e a individualidade, entre a memória e a identidade. Para o autor,

A memória emerge de um grupo que ela une, o que quer dizer que há tantas memórias quantos grupos existem; que ela é por natureza, múltipla e desacelerada, coletiva, plural e individualizada. A memória se enraíza no concreto, no gesto, na imagem, no objeto. (NORA, 1993, p. 9).

Os lugares de memória surgiriam, assim, como alternativas, estoques materiais de nossas memórias. Daí talvez a necessidade de criar bibliotecas, museus, arquivos, monumentos, santuários etc., buscando tornar possível aquilo que nossas memórias não conseguem: reter a totalidade das experiências humanas.

Em virtude de sua historicidade e das funções sociais que as bibliotecas assumem, as mesmas se transformam no refúgio contemporâneo de Mnemosyne e que, devido às práticas de sociabilidade que se engendram em torno e a partir de seu espaço, elas se mostram capazes de enunciar ou exibir uma série de construções culturais cujos referenciais expressam de maneira significativa as estruturas históricas, políticas, ideológicas e identitárias sobre as quais uma dada sociedade se constitui, nutre-se e se valoriza. (SILVEIRA, 2012, p. [2]).

Serrai (1975, p. $141^{1}$ apud SILVEIRA, 2012, p. [7]) ressalta ainda que:

[...] à memória biológica, que pertence à espécie, e à memória cerebral, que pertence ao indivíduo, acrescentou-se a biblioteca como memória coletiva das experiências existenciais, científicas e culturais do homem e da sociedade como um todo.

Retomando o conceito de patrimônio de Prats (1998), percebe-se que o autor desconsidera a escassez, a perda de funcionalidade ou a nobreza de determinados elementos como características constituintes do patrimônio. Para Prats (1998), os critérios "história", "natureza" e "genialidade" constituiriam os verdadeiros critérios que circundam os referenciais simbólicos potencialmente patrimonializáveis na sociedade contemporânea. Tais referenciais (bens materiais e imateriais) alcançariam o "status" de patrimônio cultural, verdadeiramente, quando fossem 
"ativados" por determinadas instituições, especialmente as pertencentes aos poderes políticos através dos governos locais, regionais e nacionais.

Dominique Poulot, historiador francês, ratifica a concepção de patrimônio de Prats, porém crê que não somente as instituições predominantemente políticas exercem sua influência sobre o patrimônio, como também as econômicas, através, especialmente, do turismo (POULOT, 2008). Poulot aponta a necessidade de construir a história dos bens que se tornaram patrimônio cultural, estabelecendo conexões com a realidade e descobrindo os motivos que os levaram a ser escolhidos como patrimônio, e não crer cegamente que determinado bem tombado é, aprioristicamente, patrimônio nacional.

Levando em consideração as reflexões teóricas apresentadas até o momento, conclui-se que o patrimônio cultural está na base das relações de poder de grupos sociais, proporcionando a criação de suas identidades na construção dos lugares onde vivem.

Os lugares de memória seriam, portanto, “[...] formas de manutenção e reconhecimento de existência social de determinados grupos culturais que se unem por uma memória que lhes dá os laços identitários.” (MACHADO, 2012, p. 3). Neste sentido, pode haver conflito na seleção dos bens patrimoniáveis, privilegiando-se determinados aspectos em detrimento de outros, criando um "falso" reflexo da realidade de um grupo, ou ainda, elaborando o patrimônio que, presumese, deva representar determinado grupo e excluindo-se, propositalmente, outro(s) que deva(m) cair no esquecimento.

Baczko $\left(1986,{ }^{2}\right.$ p. 310 apud MACHADO, 2012, p. 4) “[...] se refere ao imaginário social como um meio potencial de controle da vida coletiva e, especialmente, do exercício da autoridade e do poder." Tal ideia vai ao encontro da de Foucault (2008), quando este afirma que o poder está nas instituições antes mesmo de estar na sociedade e no Estado que o acolhe, ou seja, para o autor há uma relação de indissociabilidade entre as instituições e o poder.

Seguindo a linha de pensamento de Foucault (2008), é possível observar o patrimônio cultural através da sociedade civil, ou seja, o patrimônio cultural está nitidamente associado às sociedades de controle e pode ser encarado como uma categoria de pensamento e ação, uma instituição que reflete as relações de poder de 
uma comunidade ou um grupo de indivíduos.

Para atingir os objetivos a que se propõem, as instituições fazem uso de seu universo simbólico, dentre eles o patrimônio cultural de uma nação:

A memória, essa operação coletiva dos acontecimentos e das integrações do passado que se quer salvaguardar, se integra, como vimos, em tentativas mais ou menos conscientes de definir e de reforçar sentimentos de pertencimento e fronteiras sociais entre coletividades de tamanhos diferentes: partidos, sindicatos, igrejas, aldeias, regiões, clãs, famílias, nações etc. A referência ao passado serve para manter a coesão dos grupos e das instituições que compõem uma sociedade, para definir seu lugar respectivo, sua complementariedade, mas também as oposições irredutíveis. Manter a coesão interna e defender as fronteiras daquilo que um grupo tem em comum, [...] eis as duas funções essenciais da memória comum. Isso significa fornecer um quadro de referências e de pontos de referência. (POLLAK, 1989, p. 9).

Deduz-se, portanto, que a memória que une os grupos sociais a outras memórias, por sua vez, é tanto unificadora quanto excludente: ao mesmo tempo que encontra elementos comuns para reforçar o sentimento de pertencimento e, portanto, contribui com a constituição da identidade, exclui e ignora elementos que possam vir a contradizer a identidade nacional, fazendo com que

[...] desigualdades "desapareçam" porque rejeitam tudo o que não corresponde ou não se enquadra em identidades nacional, estadual e municipal, imaginadas em princípios elitistas e que potencializam no cotidiano a exclusão já contida na memória que os une. (MACHADO, 2012, p. 6).

Por outro lado, o papel do Estado é fundamental dentro da organização da memória nacional e oficial para a manutenção da identidade coletiva "inventada", pois seleciona, de forma intencional, o quadro de referências que devem ser celebrados pela memória oficial, efetivando-se uma criação estratégica da memória:

A análise das vicissitudes do patrimônio está integralmente incluída no âmbito de uma nova consciência política, não apenas no caso de medidas governamentais que tratam especificamente do patrimônio [...], mas também no fato de que a existência de uma razão patrimonial pode fornecer um ambiente para a política internacional e para a condução dos negócios em sentido amplo. (POULOT, 2008, p. 34).

Deste modo, a finalidade do patrimônio vai além da representação do 
passado das nações, tornando-se, de fato, um poderoso instrumento para a condução de políticas de governo, com alto potencial econômico.

A partir das leituras realizadas, é possível distinguir o patrimônio cultural segundo três dimensões diversas:

a) a dimensão simbólica, ligada aos valores culturais de uma comunidade e à identificação coletiva de seus membros;

b) a dimensão política, já que é um processo de construção intencional, político e mesmo estratégico das instituições às quais está subordinado;

c) e a dimensão econômica, uma nova vertente de uso e apropriação do patrimônio que se retroalimenta das duas dimensões anteriores, e que tem no turismo cultural sua manifestação mais contundente.

Percebe-se, hoje em dia, o crescimento da importância dada ao patrimônio pelo poder público, o que demonstra a "descoberta" da possibilidade de criação e uso estratégico de políticas públicas voltadas à proteção e valorização do patrimônio e de sua potencialidade como forma de governabilidade, ocorrendo muitas vezes uma supervalorização do passado e dos patrimônios culturais pelas sociedades em geral, incluindo situações onde há um excesso de necessidade de enquadramento patrimonial. Levando em consideração as três dimensões do patrimônio acima mencionadas, é passível de entendimento este fenômeno de supervalorização, já que em qualquer uma das situações o patrimônio cultural poderá ser utilizado para alcançar os propósitos ideológicos e econômicos dos poderes que o ativam.

\section{Patrimônio bibliográfico e bibliotecas nacionais}

A história das bibliotecas está diretamente relacionada à história do livro e da escrita. As primeiras bibliotecas que se tem notícia surgiram há mais ou menos 3.000 anos e tinham como propósito guardar as tabuletas de argila que registravam informações comerciais e legais (compra de grãos, venda de terrenos, estatutos dos sacerdotes, posições das estrelas, textos religiosos etc.).

Nos séculos subsequentes, muitos textos foram copiados e conservados por muçulmanos e cristãos, tendo sido os monges grandes contribuidores para a 
preservação da literatura e do conhecimento registrado, realizando cópias manuscritas das obras (monges copistas).

No século XII surgem as primeiras universidades, na Europa. Estas instituições, inicialmente, não dispunham de bibliotecas. A primeira biblioteca universitária que se tem notícia é a da Universidade de Heidelberg, na Alemanha, criada em 1386. Neste período as bibliotecas não emprestavam livros: estes eram acorrentados às mesas de leitura e só poderiam ser consultados no local. A partir do século XVI a biblioteca se transforma e passa a ter como característica a localização acessível, caráter intelectual e civil, visando à democratização da informação e tornando-se, muitas vezes, especializada em diferentes áreas do conhecimento.

O surgimento das bibliotecas nacionais remonta ao século XVIII, na Europa, em meio à Revolução Francesa. Diferiam das demais bibliotecas em função de sua missão: preservar a memória bibliográfica nacional.

Apesar de ter surgido há vários séculos, as discussões em torno do conceito de biblioteca nacional e sua missão só passou a ser objeto de reflexão a partir da segunda metade do século XX, especialmente em 1950 quando, em ocasião da Conferência Internacional sobre a Melhoria dos Serviços Bibliográficos, a Organização das Nações Unidas para a Educação, a Ciência e a Cultura (UNESCO) recomendou que se criasse, em cada país, um Centro de Informação Bibliográfica Nacional. No Brasil esta recomendação resultou na criação do Instituto Brasileiro de Bibliografia e Documentação, em 1954 (MONTE-MÓR, 1987).

A partir de então as bibliotecas nacionais e sua importância para a construção e preservação do patrimônio bibliográfico passaram a fazer parte da agenda de discussões dos países, especialmente os europeus. Em 1970 a UNESCO, através de suas Recomendações relativas à normalização internacional de estatísticas de bibliotecas, define as bibliotecas nacionais como:

[...] bibliotecas que, independente de seus títulos, são responsáveis pela aquisição e conservação de exemplares de todas as publicações significativas editadas no país e funcionam como biblioteca depositária do conhecimento humano. (UNESCO, 1978³ apud ANDRADE, 2009, p. 20). 
Assim, portanto, à Biblioteca Nacional do Brasil coube a incumbência de salvaguardar a produção intelectual brasileira.

Reavendo os teóricos apresentados na seção anterior, através dos quais se observa que o patrimônio cultural está na base das relações de poder, proporcionando a criação das identidades coletivas dos grupos sociais, seria plausível pensar nas instituições bibliotecas nacionais enquanto:

a) lugares de memória, já que são, oficialmente, lugares onde se guarda e preserva a memória escrita das nações às quais pertencem;

b) patrimônios tangíveis, já que tanto seus prédios quanto seus acervos são reconhecidos como patrimônios nacionais através dos instrumentos formais de certificação e validação do patrimônio;

c) poderosos instrumentos para a condução das políticas de governos, especialmente quando se voltam as atenções para duas importantes questões diretamente relacionadas à ampliação de seus acervos, (1) a sua subordinação administrativa, que as condiciona às ações dos governos vigentes e, deste modo, certamente influencia todas as ações da Biblioteca Nacional, inclusive as de cunho técnico como o desenvolvimento da sua coleção e a disponibilização desta ao grande público, e (2) o principal recurso de preservação da memória nacional que é o depósito-legal, através do qual a Biblioteca recebe grande parte de suas doações.

Através do exposto, verifica-se que as bibliotecas nacionais, observadas as bases de sua criação, possuem missão social, política e civilizadora, e desta forma contribuem tanto para a formação de uma identidade coletiva quanto para o estabelecimento de vínculos entre o patrimônio e as nações às quais pertencem.

\subsection{Biblioteca Nacional (Brasil)}

A Biblioteca Nacional (BN), juntamente com sua biblioteca subordinada - a Biblioteca Euclides da Cunha (localizada na cidade do Rio de Janeiro) e o Instituto Nacional do Livro (INL), com sua Biblioteca Demonstrativa (localizada em Brasília) constituem a Fundação Biblioteca Nacional (FBN), entidade de direito público vinculada ao Ministério da Cultura (MinC). A FBN, por sua vez, é responsável pelas políticas públicas para o Livro, Leitura e Literatura e Biblioteca, sistematizando suas 
ações em concordância com o Plano Nacional da Cultura e o Plano Nacional de Livro e Leitura (FUNDAÇÃO BIBLIOTECA NACIONAL, 2013).

A FBN, em ocasião anterior, esteve subordinada ao antigo Ministério do Interior e Justiça, depois ao Ministério da Educação e Saúde. Com a criação do Ministério da Saúde, passou integrar o Ministério da Educação e Cultura. Em 1981, o órgão passou à administração indireta, fazendo parte da Fundação Nacional PróMemória, até o ano de 1984, quando, junto com o INL, passou a constituir a Fundação Nacional Pró Leitura, até a criação da Fundação Biblioteca Nacional, em 1990.

As competências institucionais da Fundação podem ser sintetizadas em dois eixos fundamentais, a saber:

[...] o primeiro diz respeito à salvaguarda da memória cultural bibliográfica brasileira, constituída na FBN por um acervo de mais de oito milhões de itens, reconhecido mundialmente como um verdadeiro tesouro, englobando todas as ações referentes à preservação e à difusão de seu acervo. O segundo concerne à vida cultural do país, destacando-se as políticas públicas do livro e da leitura, da literatura e bibliotecas, em especial a implantação e modernização de bibliotecas pelo Brasil, o fomento à mediação de leitura, a coordenação de diversas ações com objetivo de projetar de forma duradoura a literatura brasileira não só no Brasil, como também nos principais mercados do mundo, além da coordenação de ações que estimulem a criação, produção e a venda de livros com preços acessíveis à população. (FUNDAÇÃO BIBLIOTECA NACIONAL, 2013, p. 6, grifo nosso).

Conforme exposto, a fim de efetivar as ações do primeiro eixo, tem-se a BN, uma das 10 maiores bibliotecas nacionais do mundo e a maior da América Latina, sendo responsável pela difusão e preservação da memória bibliográfica brasileira. O segundo eixo diz respeito à área de Livro, Leitura, Literatura e Bibliotecas, à qual compete a coordenação do Sistema Nacional de Bibliotecas Públicas (SNBP) e a promoção da difusão do livro, da literatura e da leitura em âmbitos nacional e internacional.

A BN tem suas origens na Real Biblioteca, pertencente à Família Real Portuguesa. Ao se transferir de Portugal para o Brasil, em 1807, esta trouxe em meio à bagagem uma quantidade de obras equivalente a um terço da totalidade do acervo, sendo a segunda remessa de livros enviada em 1810. A terceira remessa de livros nunca saiu de Portugal. 
"Na frota vieram os tesouros do Estado: ouro, diamantes do monopólio, jóias, prataria, até paramentos da Capela Real. Vieram os arquivos das repartições públicas, a Biblioteca Real da Ajuda, os Manuscritos da Coroa e os do Infantado." (MORAES, 2006, p. 91).

O montante de itens vindos para o Brasil contabilizou cerca de $60 \mathrm{mil}$ exemplares, entre livros, manuscritos, mapas, estampas, moedas e medalhas. Quando, em 1821, D. João VI retornou a Portugal, deixou no Brasil a Real Biblioteca, acrescida do acervo do conde da Barca, porém levou consigo parte dos "Manuscritos da Coroa". (FUNDAÇÃO BIBLIOTECA NACIONAL, 2006; SCHWARCZ; AZEVEDO; COSTA, 2007).

A Real Biblioteca, fundada no Rio de Janeiro em 29 de outubro de 1810, ocupou diferentes prédios, os quais nunca se mostraram suficientemente adequados para acomodar o precioso acervo. Somente em 1910 transferiu-se definitivamente para o prédio situado na Avenida Rio Branco, $\mathrm{n}^{\circ}$ 219-39, local ocupado pela instituição até os dias de hoje (PORTELLA, 2010).

A Real Biblioteca integrava, inicialmente, duas coleções distintas: a Biblioteca do Rei e a Biblioteca da Casa do Infantado (destinada ao uso dos príncipes). Em 1822 passou a denominar-se Biblioteca Imperial e Pública; em 1876 mudou novamente de nome para Biblioteca Nacional do Rio de Janeiro e, posteriormente, em 1948, adotou a designação que persiste até os dias de hoje: Biblioteca Nacional. (SCHWARCZ; AZEVEDO; COSTA, 2007; ANNAES, 1883 1884; PORTELLA, 2010).

Oficialmente estabelecida, a Biblioteca continuou a ampliação de seu acervo através de doações e compras, mas principalmente através das "propinas", que se constituíam na obrigatoriedade da entrega de um exemplar de todo material impresso nas oficinas tipográficas portuguesas e, posteriormente, na Impressão Régia. Assim ocorreu até 1907, quando o sistema de "propinas" deu origem ao Decreto n. 1.825 que regula o depósito legal, ainda em vigor.

É através do cumprimento da lei do Depósito Legal, que a BN, ao receber um exemplar do que se publica no Brasil, vai-se tornando a guardiã da memória gráfica brasileira. A lei do Depósito Legal é o mais poderoso auxiliar da Biblioteca Nacional no cumprimento de sua finalidade de proporcionar a informação cultural 
nas diferentes áreas do conhecimento humano com base na produção intelectual brasileira e nas obras mais significativas da cultura estrangeira, que constituem o sempre crescente acervo bibliográfico e hemerográfico, cujo conjunto lhe cumpre preservar (FUNDAÇÃO BIBLIOTECA NACIONAL, 2006).

Atualmente a BN dispõe de um acervo diversificado, contabilizado em mais de 8 milhões de exemplares. Ao acervo inicial da Real Biblioteca foram incorporadas outras coleções, cujos antigos proprietários eram pessoas ilustres e de grande destaque no cenário nacional. Possui, ainda, significativo acervo de obras raras, música, manuscritos, iconografia, entre outros.

\section{Considerações acerca das relações entre bibliotecas, memória e identidade}

Através do exposto nas seções anteriores, é possível observar que as bibliotecas nacionais apresentam duas dimensões distintas: a) a dimensão simbólica, ligada aos valores culturais da nação e à identificação coletiva de seus membros; b) a dimensão política, já que são o resultado de um processo de construção intencional (político) das instituições às quais estão subordinadas.

A Biblioteca Nacional brasileira está subordinada e sujeita às diretivas impostas por seus administradores, os quais direcionam suas políticas em consonância com as decisões do governo vigente. Sendo assim, infere-se a existência de autoridade no desenvolvimento do acervo, indo ao encontro dos objetivos políticos e ideológicos da nação. Chartier (1998, p. 70) chama a atenção para este processo: “[...] a separação dos livros que são imprescindíveis de se possuir dos que podem (ou devem) ser negligenciados é um dos meios de disfarçar a impossível universalidade da biblioteca".

A composição do acervo da Biblioteca Nacional, assim como o de outras bibliotecas semelhantes, não foi reunida por corresponder exclusivamente à organização de uma instituição, mas sim porque as suas obras refletiam uma necessidade de informação. Sabendo que um conjunto de obras, acidentalmente reunidas, poderiam atuar como memória da nação, então, da mesma forma, seria possível afirmar que esta mesma memória também pode ser "revelada pelas obras 
literárias que fixam momentos de sensibilidade social e exprimem formas de tomada de consciência." (BETHENCOURT; CURTO, 1991 apud CABRAL, 2013, p. 15).

\begin{abstract}
A biblioteca também é um espelho do seu tempo, do seu possuidor, da instituição em que, naturalmente, se anicha entre parentes mais ou menos próximos e conhecidos: os arquivos, os gabinetes de curiosidades, os museus ou as galerias. [...] Não é, portanto, indiferente conhecer o que cada biblioteca reúne, classifica e conserva. O que está dentro guardado, arrumado, quiçá classificado - veicula a pressão exterior. Uma vez entendidos os critérios de selecção de autores e obras que uma biblioteca pondera adquirir para constituir as suas colecções, podemos então com propriedade discutir se essa biblioteca ocupa, ou não, um lugar significativo na construção da identidade colectiva. (CABRAL, 2013, p. 21-22).
\end{abstract}

Ao retomar a trajetória histórica da Biblioteca Nacional, percebe-se a preocupação em preservar o patrimônio bibliográfico brasileiro, o qual pode ser definido como "[...] um conjunto de documentos, de origem pública ou privada, existentes no âmbito de uma nação, de um estado ou de um município, formado através de sua importância administrativa, histórica e cultural.” (ANDRADE, 2009, p. 25). A Biblioteca Nacional, por sua vez, não advém de uma coleção real doada ou cedida ao país colonizado, muito pelo contrário, custou caro à jovem nação, que a adquiriu oficialmente em 1825, mediante a Convenção Adicional ao Tratado de Paz e Amizade celebrado entre Brasil e Portugal. A aquisição da Real Biblioteca “[...] está vinculada ao reconhecimento do Brasil como nação autônoma." (PORTELLA, 2010, p. 3).

É necessário ainda, levar em conta a trajetória política e administrativa da Biblioteca Nacional, a fim de melhor compreender os meandros de sua atuação enquanto repositório da memória coletiva. Neste sentido, observa-se a necessidade de maior aprofundamento em diversas questões apontadas no trabalho, as quais a autora pretende desenvolver de maneira satisfatória na sua tese de doutoramento.

\title{
Referências
}

ANNAES DA BIBLIOTHECA NACIONAL DO RIO DE JANEIRO. Rio de Janeiro, v. 11, 1883-1884. Disponível em: 〈http://bit.ly/1N9h3ux >. Acesso em: 26 nov. 2014. 
ANDRADE, R. M. N. Bibliotecas: lugar de memória e preservação: o caso da Biblioteca Nacional do Brasil. Patrimônio e Memória, São Paulo, v. 4, n. 2, p. 17 34, jun. 2009. Disponível em: 〈http://bit.ly/15Lf2AR>. Acesso em: 26 nov. 2014.

CABRAL, M. L. R. Património bibliográfico e bibliotecas na construção da identidade colectiva: entre um conceito e o seu desenvolvimento, 1750-1800. 2013. Tese (Doutorado em História Moderna) - Universidade Nova de Lisboa, Faculdade de Ciências Sociais e Humanas, Lisboa, 2013. Disponível em: $\langle$ http://bit.ly/1pAVJTJ $\rangle$. Acesso em: 26 nov. 2014.

CANDAU, J. Memória e identidade. São Paulo: Contexto, 2011.

CHARTIER, R. A ordem dos livros: leitores, autores e bibliotecas na Europa entre os séculos XIV e XVIII. 2. ed. Brasília: UNB, 1998.

FOUCAULT, M. Aula de 4 de abril de 1979. In: FOUCAULT, M. Nascimento da biopolítica. São Paulo: Martins Fontes, 2008. p. 397-430.

FUNARI, P. P.; PELEGRINI, S. C. A. Patrimônio histórico e cultural. 2. ed. Rio de Janeiro: Zahar, 2009.

FUNDAÇÃO BIBLIOTECA NACIONAL (Brasil). Histórico. Rio de Janeiro, 2006. Disponível em: 〈http://bit.ly/1tOrYNz>. Acesso em: 26 nov. 2014.

FUNDAÇÃO BIBLIOTECA NACIONAL (Brasil). Relatório de gestão do exercício de 2012. Rio de Janeiro, 2013. Disponível em: 〈http://bit.ly/1uXQvgA〉. Acesso em: 27 nov. 2014.

HALBWACHS, M. Los marcos sociales de la memória. Barcelona: Anthropos, 2004.

HALBWACHS, M. A memória coletiva. São Paulo: Vértice, 1990.

MACHADO, I. A. P. História, patrimônio e cidade: uma questão política. Revista Memória em Rede, Pelotas, v. 2, n. 7, p. 1-14, jul./dez. 2012. Disponível em: $\langle$ http://bit.ly/1tqIq41 >. Acesso em: 13 nov. 2014.

MATHEUS, L. Memória e identidade segundo Candau. Revista Galáxia, São Paulo, n. 22, p. 302-306, dez. 2011. Disponível em: 〈http://bit.ly/17DnfXK〉. Acesso em: 12 nov. 2014.

MONTE-MÓR, J. Patrimônio bibliográfico e a problemática das bibliotecas nacionais. Revista do Patrimônio Histórico e Artístico Nacional, Rio de Janeiro, n. 22, p. 163-170, 1987. Disponível em: 〈http://bit.ly/12gfJjo >. Acesso em: 26 nov. 2014.

MORAES, R. B. Livros e bibliotecas no Brasil colonial. 2. ed. Brasília: Briquet de Lemos Livros, 2006. 
NORA, P. Entre memória e história: a problemática dos lugares. Projeto História: revista do Programa de Estudos pós-Graduados em História e do Departamento de História, São Paulo, n. 10, p. 7-28, dez. 1993. Disponível em: <http://bit.ly/1c8w8Mn>. Acesso em: 12 out. 2013.

POLLAK, M. Memória e identidade social. Estudos Históricos, Rio de Janeiro, v. 5, n. 10, p. 200-212, 1992. Disponível em: 〈http://bit.ly/1vzLMFv〉. Acesso em: 12 nov. 2014.

POLLAK, M. Memória, esquecimento, silêncio. Estudos Históricos, Rio de Janeiro, v. 2, n. 3, p. 3-13, 1989. Disponível em: 〈http://bit.ly/1uXQMjw〉. Acesso em: 12 nov. 2014.

PORTELLA, C. M. Releitura da Biblioteca Nacional. Estudos Avançados, São Paulo, v. 24, n. 69, p. 1-18, 2010. Disponível em: 〈http://bit.ly/1B2oaOj〉. Acesso em: 27 nov. 2014.

POULOT, D. Um ecossistema do patrimônio. In: CARVALHO, C. S. R. et al. (Org.). Um olhar contemporâneo sobre a preservação do patrimônio cultural material. Rio de Janeiro: Museu Histórico Nacional, 2008. p. 26-43. Disponível em: <http://bit.ly/1Ctlkne>. Acesso em: 18 nov. 2014.

PRATS, L. El concepto de patrimonio cultural. Política y Sociedad, Madrid, n. 27, p. 63-76, 1998. Disponível em: 〈http://bit.ly/1B2oblA〉. Acesso em: 25 nov. 2014.

SCHWARCZ, L. M.; AZEVEDO, P. C.; COSTA, A. M. A longa viagem da biblioteca dos reis: do terremoto de Lisboa à independência do Brasil. 2. ed. São Paulo: Companhia das Letras, 2007.

SILVEIRA, F. J. N. Biblioteca, memória e identidade social. Perspectivas em Ciência da Informação, Belo Horizonte, v. 15, n. 3, p. 67-86, set./dez. 2010. Disponível em: < http://bit.ly/1NTF4Rj >. Acesso em: 12 out. 2013.

SILVEIRA, F. J. N. Sendas entre o visível e o invisível: a biblioteca como "lugar de memória" e de preservação do patrimônio. DataGramaZero: revista de informação, Rio de Janeiro, v. 13, n. 5, p. [1-16], out. 2012. Disponível em:

<http://bit.ly/1PjEFeA>. Acesso em: 12 out. 2013. 


\title{
Memory, heritage, national libraries and the construction of collective identity
}

\begin{abstract}
This work aims to contribute to the understanding of the relationship between libraries and the construction of collective memory and its implications for the preservation of national cultural heritage. The study presents a theoretical review of memory and heritage, based on important researchers in the field. Also prepare a review about the context of appearance of national libraries, based on contemporary authors. In sequence, makes comments about the institutional mission of national libraries, tracing a brief outline of the historical trajectory of the brazilian National Library, demonstrating its role in safeguarding the bibliographic heritage of the country.
\end{abstract}

Keywords: Social memory. Cultural heritage. Bibliographic heritage. National Library (Brazil).

1 SERRAI, A. História da biblioteca como evolução de uma idéia e de um sistema. R. Esc. Bibliotecon. UFMG, Belo Horizonte, v. 4, n. 2, p. 141-161, set. 1975.

${ }^{2}$ BACZKO. B. Imaginação Social. In: ENCICLOPÉDIA EINAUDI. Porto: Casa da Moeda, 1986. v. 5.

${ }^{3}$ UNESCO. Recomendação da UNESCO sobre a normalização internacional das estatísticas relativas a bibliotecas. Tradução de Jorge Peixoto. 1970. R. bras. Bibliotecon. Doc., v. 11, n. 1-2, p. 76-82, jan./jun. 1978.

4 BETHENCOURT, F.; CURTO, D. R. (Org.). A memória da nação. In: COLÓQUIO DO GABINETE DE ESTUDOS DE SIMBOLOGIA, 1987, Lisboa. [Actas]. Lisboa: Sá da Costa, 1991.

Recebido: 08/04/2015

Aceito: $23 / 06 / 2015$ 